\title{
PROFISSÃO DOCENTE: ELEMENTOS DEMARCADORES DAS REPRESENTAÇÕES SOCIAIS DE PROFESSORES EM INÍCIO DE CARREIRA
}

\author{
PROFESIÓN DOCENTE: CAMINOS REPRESENTACIÓN DE ELEMENTOS \\ SOCIAL DE LOS PROFESORES EN LA CARRERA INICIO
}

\begin{abstract}
TEACHING PROFESSION: DEMARCATING ELEMENTS OF THE SOCIAL REPRESENTATIONS OF TEACHERS IN THE BEGINNING OF CAREER
\end{abstract}

Laeda Bezerra MACHADO ${ }^{1}$

RESUMO: O artigo aborda as representações sociais da profissão docente entre diferentes grupos de professores iniciantes em atuação na educação básica. Apresenta-se os elementos demarcadores dessas representações. Utilizou-se como referencial a abordagem societal das representações sociais. Trata-se de um estudo de natureza qualitativa que envolveu 44 professores de escolas públicas de Recife e Região Metropolitana com até cinco anos de carreira. Os dados foram recolhidos através de entrevista semiestruturada e processados através do software Alceste. Como elementos demarcadores das representações sociais da profissão docente detectamos: a transmissão e mediação de conhecimentos, possibilidade de formar sujeitos, o compromisso e a responsabilidade envolvidos na tarefa de educar e, principalmente, a desvalorização e falta de reconhecimento social do professor. A pesquisa reforça a necessidade de elaboração de programas formativos que ofereçam maior suporte ao trabalho do docente iniciante.

PALAVRAS-CHAVE: Profissão docente. Representações sociais. Professor iniciante.

RESUMEN: El artículo analiza las representaciones sociales de la profesión docente entre los diferentes grupos de profesores principiantes en la acción en la educación básica. Presenta los elementos caminos de estas representaciones. Fue utilizado como una referencia a enfoque social de las representaciones sociales. Se trata de un estudio cualitativo que involucró a 44 maestros de las escuelas públicas en Recife y el área metropolitana con hasta cinco años de carrera. Los datos fueron recolectados a través de semi-estructurada y procesados a través del software Alceste entrevista. Como elementos de sendas representaciones sociales de la profesión docente: detectado la transmisión y la mediación del conocimiento, posibilidad de formar el compromiso y la responsabilidad que implica la tarea de educar, y especialmente la devaluación y la falta de reconocimiento social del maestro. La investigación refuerza la necesidad del

1 Universidade Federal de Pernambuco (UFPE), Recife - PE - Brasil. Professora Associado I do Departamento de Administração Escolar e Planejamento Educacional e do Programa de Pós-Graduação em Educação da UFPE. Bolsista de produtividade em pesquisa do CNPq. Doutora em Educação pela Universidade Federal do Rio Grande do Norte. ORCID: <https://orcid.org/0000-0002-9524-0319 >. Email: laeda01@gmail.com

RIAEE - Revista Ibero-Americana de Estudos em Educação, Araraquara, v. 13, n. 03, p. 1132-1148, jul./set., 2018. 
desarrollo de programas de formación para proporcionar un mayor apoyo a la labor de los profesores noveles.

PALABRAS CLAVE: Profesión docente. Representaciones sociales. El profesor principiante.

ABSTRACT: The article addresses the social representations of the teaching profession among different groups of beginning teachers in basic education. The demarcating elements of these representations are presented. The societal approach of social representations was used as reference. This is a qualitative study that involved 44 teachers from public schools in Recife and Metropolitan Region with up to five years of career. The data were collected through a semi-structured interview and processed through Alceste software. As elements of the social representations of the teaching profession, we detect: the transmission and mediation of knowledge, the possibility of forming subjects, the commitment and responsibility involved in the task of educating, and especially the devaluation and lack of social recognition of the teacher. The research reinforces the need for elaboration of training programs that offer greater support to the work of the beginning teacher.

KEYWORDS: Teaching profession. Social representations. Beginning teacher.

\section{Introdução}

Nossa preocupação com as representações sociais dos professores e seus efeitos sobre a prática docente não é recente. Há mais uma década coordenando e orientando pesquisas com professores do ensino fundamental, temos percebido que têm sido comuns os desafios enfrentados por professores em início de carreira. Especialmente, nas pesquisas sobre representações sociais e práticas na escola, temos indicado que os professores iniciantes na profissão são aqueles que apresentam representações mais negativas da docência, os que consideram os conteúdos dos cursos de formação excessivamente teóricos e distanciados da realidade das escolas, além de minimizarem sua contribuição para o desempenho de suas atividades docentes.

Em estudo sobre as representações sociais e práticas de professores de sucesso nos ciclos de aprendizagem, não localizamos professores que fossem ao mesmo tempo considerados de sucesso e estivessem no início da carreira. Em geral os professores considerados de sucesso, ou seja, aqueles mais comprometidos com a aprendizagem dos estudantes são os que já superaram o choque de realidade do início da docência. Garcia (1999, p. 28) denomina choque de realidade "o período de confrontação inicial do 
professor com as complexidades da situação profissional e as condições de permanência deste profissional na docência, apesar de todas as agruras que vivencia".

Huberman (1995) discute os diferentes estágios da carreira e caracteriza como inicial o período do ingresso até três anos de profissão. Para o autor é o momento da docência no qual o professor se depara com a realidade, nem sempre a idealizada por ele em sua formação inicial.

Garcia (1999 p. 113) considera esse estágio inicial da carreira como "um período de tensões e aprendizagens intensivas em contextos geralmente desconhecidos, e durante o qual os professores principiantes devem adquirir conhecimento profissional além de conseguirem manter um certo equilíbrio pessoal”. A inserção na carreira docente, como salienta Lima et al (2006), é um momento peculiar, marcado por inúmeras dificuldades.

A produção acadêmica sobre o professor iniciante no Brasil tem crescido, e estudos do tipo estado do conhecimento sobre o tema, como os de Papi e Martins (2009), Corrêa e Portella (2012), Papi e Carvalho (2013) revelam que, embora o campo da formação de professores venha ganhando cada vez mais destaque, o início da docência configura-se como uma temática ainda pouco explorada nesse campo mais abrangente. As autoras, mesmo reconhecendo que o número de estudos sobre o professor em início de carreira aumentou, deixam claro que eles estão mais concentrados nos anos iniciais da educação básica e educação superior, e reiteram a importância da continuidade dos investimentos em pesquisas sobre o início da docência.

Outro estudo da produção sobre o tema foi desenvolvido por Papi e Carvalho (2013). Ao abordarem os enfoques das produções brasileiras sobre o professor iniciante em publicações de um evento internacional, as autoras mostram que esses enfoques estão muito mais direcionados para explicitar as dificuldades e dilemas enfrentados pelos ingressantes do que em busca de intervenções que busquem amenizá-los.

Em estudos com professores em escolas públicas municipais (MACHADO; ANICETO, 2010; MACHADO, 2012) aos quais já nos referimos, alguns depoimentos de docentes iniciantes sobre os seus desafios cotidianos e os desejos que manifestavam por assumir outra função que não fosse à docência em sala de aula nos chamaram atenção. No entanto, foi o fato de não termos localizado professores que fossem ao mesmo tempo bem sucedidos e iniciantes na carreira, o que mais nos mobilizou a realizar um estudo com profissionais nessa condição. Assim, este artigo é parte de um 
estudo mais abrangente e aborda as representações sociais da profissão docente entre diferentes grupos de professores de educação básica em início de carreira.

\section{Referencial teórico}

Como referencial, adotamos a Teoria das Representações Sociais. A referida teoria, proposta por S. Moscovici, além de heuristicamente útil para analisar complexos fenômenos sociais tem sido capaz, devido ao seu caráter interdisciplinar, de reorientar tradicionais campos de estudo (DOISE, 2001).

Estudamos as representações sociais da profissão docente de professores iniciantes na carreira a fim de saber seus elementos demarcadores para esse grupo, levando em conta as tomadas de posições desses atores sociais frente às demandas da docência. Em termos gerais, podemos dizer que as representações sociais são saberes do senso comum que orientam as práticas e as condutas dos sujeitos em relação aos outros e ao mundo. O sujeito, ao representar, atua sobre o objeto, não apenas o reproduz. Suas interações com os objetos e com outros sujeitos na realidade determinam a construção de suas representações do mundo e das coisas que lhes são significativas. A comunicação social media e favorece essas elaborações (MOSCOVICI, 1978).

A comunicação ganha lugar de destaque na teoria. "A comunicação social, sob seus aspectos interindividuais, institucionais e midiáticos, aparece como condição de possibilidade de determinação das representações e do pensamento sociais" (JODELET, 2001, p. 29).

A valorização do senso comum, que originalmente era um conhecimento desvalorizado, ganhou destaque no trabalho de Moscovici. Com sua tese o autor mostra como os sujeitos tomam para si os conhecimentos científicos num processo de recriação e articulação que gera ações e comportamentos que vão conduzindo suas relações.

Vale salientar, entretanto, que nem todo conhecimento do senso comum pode ser denominado de representação social, uma vez que o objeto ${ }^{2}$ de representação social deve ser polimorfo, isto é, passível de assumir formas diferentes para cada contexto social e, ao mesmo tempo, ter relevância cultural para o grupo. Não obstante, a relevância cultural do objeto pode ser identificada através das conversações e outras

${ }^{2}$ Objeto pode ser tanto uma pessoa, quanto uma coisa, um acontecimento material, psíquico ou social, um fenômeno natural, uma ideia, uma teoria pode ser real quanto imaginário ou mítico. (JODELET, 2001 p. 22). 
manifestações do sujeito na sociedade. Moscovici afirma que "pessoas e grupos criam representações no decurso da comunicação" (MOSCOVICI, 2012).

Fica evidenciado que as representações estão vinculadas à comunicação, são geradas nas situações e relações sociais e mobilizam a atividade cognitiva dos sujeitos para compreender o mundo. Constituem um saber construído, compartilhado nas relações sociais e permeado pela comunicação.

Moscovici (2012) nos remete a pensar que, com a evolução das ciências e a velocidade da circulação das informações, é cada vez mais necessário explicar a realidade, tornar os conhecimentos acessíveis. Contudo, ele aponta a dificuldade em se transformar palavras, ideias ou seres não familiares em algo familiar. Para o autor, essas representações são construídas de modo interdependente, mediante dois processos: a objetivação e a ancoragem.

No que concerne à objetivação, refere-se ao processo de materialização do objeto abstrato, ou seja, “[...] arte de transformar uma representação na realidade da representação; transformar a palavra que substitui a coisa, na coisa que substitui a palavra" (MOSCOVICI, 2012, p. 71). A objetivação permite comparar algo que não conhecemos a uma coisa, pessoa ou conceito que nos é familiar. É a ligação de uma palavra a uma imagem em um processo de seleção. Segundo o autor, nem todas as palavras podem ser ligadas a imagens, pois estas precisam estar integradas a um padrão de núcleo figurativo, que se define como um complexo de imagens selecionadas e legitimadas pela sociedade mediante as crenças e referências culturais.

A ancoragem transforma um objeto não familiar em algo conhecido. Uma operação mental faz com que o objeto se ajuste e se integre a categorias comuns, incorporando suas características. $\mathrm{O}$ ancorar não é um ato neutro, implica necessariamente em julgamento, uma avaliação. Para Moscovici (2012, p. 61), “ancorar é classificar e dar nome a alguma coisa”. Assim a classificação consiste em pegar o objeto, confinar a um conjunto de comportamentos e regras que ditam o que é ou não é permitido em relação a todos os sujeitos pertencentes a determinado grupo.

Em síntese, a objetivação e a ancoragem possuem características distintas, todavia se complementam, são processos simultâneos. Neste artigo sobre as representações sociais da profissão construídas por docentes iniciantes, tentaremos evidenciar os elementos que demarcam essas representações.

O campo das representações sociais, originalmente desenvolvido por Moscovici, desdobra-se em três correntes: a primeira aprofunda a grande teoria com as 
contribuições de Denise Jodelet; a segunda, de viés sociológico, possui como principal protagonista Willem Doise, e a terceira enfatiza a dimensão cognitivo-estrutural, desenvolvida por J.C. Abric. Este texto, não desprezando a vertente original, mas dialogando com ela, adota a abordagem societal, de Williem Doise e colaboradores, para o estudo da profissão docente entre diferentes grupos de professores iniciantes.

A abordagem societal abrange o individual e o coletivo, ou seja, articula explicações de ordem individual com explicações de ordem societal, evidenciando que os processos dos quais os indivíduos dispõem para viver em sociedade são orientados por dinâmicas sociais (interacionais, posicionais ou de valores e de crenças gerais). Sendo assim, Doise e o grupo de Genebra privilegiam a dinâmica das relações sociais vividas pelos grupos no interior da sociedade para a construção das representações. Segundo o autor, as interações sociais dos indivíduos concorrem para o aparecimento e o desenvolvimento das operações cognitivas, que se organizam a partir de representações que vão sendo produzidas e partilhadas pelos grupos sociais. Seguindo a abordagem societal procuramos detectar os elementos demarcadores das representações sociais da profissão docente para professores iniciantes que atuam na educação infantil, nos anos iniciais e finais do ensino fundamental.

\section{Metodologia}

Estudos fundamentados na Teoria das Representações Sociais em geral são estudos de abordagem qualitativa, uma vez que é a que mais se apropria ao estudo de sentidos e significados atribuídos pelos sujeitos a objetos diversos. Reiteramos que, conforme Jodelet (2001), através de suas experiências e interações, o sujeito vai construindo um saber através do qual os conceitos materiais ou abstratos (acontecimentos, ideias, pessoas, noções ou sentimentos) adquirem sentidos. Admitimos, pois, que em torno da profissão docente circula um conjunto de sentidos e significados que orienta as práticas dos professores iniciantes na docência na escola pública.

A opção por esta abordagem foi feita com base em Minayo (2008), segundo o qual a investigação qualitativa trabalha com valores, crenças, hábitos, atitudes, representações, opiniões, e adequa-se a aprofundar a complexidade de fatos e processos particulares a indivíduos e grupos. 
Os participantes da pesquisa são 44 professores iniciantes na profissão docente, ou seja, professores com até cinco anos no exercício da profissão ${ }^{3}$. São 36 professoras e 8 professores. Para selecioná-los, foram considerados os seguintes critérios: estar atuando como professor na Educação Infantil, Ensino Fundamental (anos iniciais e finais) há no máximo cinco anos, ter concluído o curso de graduação (licenciatura).

O tempo de carreira dos docentes participantes estava assim distribuído: 7 estavam com até um ano de exercício profissional; 15 com até dois anos; 12 com até três anos, 5 com até quatro anos e 5 com até cinco anos de experiência docente. Do grupo participante 20 atuavam nos anos finais do ensino fundamental; 13 eram professores dos anos iniciais e 11 exerciam a docência na educação infantil.

Como procedimento de coleta de dados utilizamos a entrevista semiestruturada. Entendemos que esse procedimento se adequa à investigação porque, como admite Moscovici (1978), nas conversações são veiculados valores que permitem ao pesquisador aproximar-se de objetos simbólicos, como as representações sociais.

Os dados recolhidos com as entrevistas foram transcritos, editados e analisados com auxílio do software Análise Lexical Contextual (ALCESTE). O programa foi desenvolvido na França nos anos 1970 e introduzido no Brasil no final da década de 90. Por meio dele é possível se fazer uma análise estatística de dados textuais. O programa gera classes lexicais formadas por Unidades de Contexto Elementar (UCEs) ${ }^{4}$. As classes são formadas por palavras de contexto similar e estáveis, ou seja, com vocabulário semelhante. As "classes podem indicar representações sociais ou campos de imagem sobre um dado objeto, ou somente aspectos de uma mesma representação social” (CAMARGO, 2005, p. 517). Em contato com os campos semânticos (palavras) e os respectivos contextos (UCEs) em que elas foram verbalizadas, o pesquisador pode apreender as representações sociais subjacentes ao vocabulário exposto nas classes.

\section{Resultados: elementos demarcadores das representações sociais da profissão docente por professores em início de carreira}

\footnotetext{
${ }^{3}$ Utilizamos o critério estar até 5 anos na docência que, seguindo a orientação de Garcia (1999), pode ser considerado iniciante na profissão.

${ }^{4}$ As Unidades de Contexto Elementar (UCEs) são segmentos de texto, extraídos pelo software em função do corpus analisado, nesses segmentos são encontradas as palavras que compõem cada classe. As UCEs são agrupadas em função da semelhança e diferença no vocabulário, depois disso são extraídas as palavras significativas para cada classe.
} 
Como resultado do processamento do software, obtivemos um total de 864 Unidades de Contexto Elementares (UCEs), distribuídas em cinco classes. As classes têm sua origem em dois eixos principais: o primeiro diz respeito à sistematização dos conteúdos dos depoimentos que se referem ao ser professor, envolvendo a escolha e as perspectivas profissionais. Esse material discursivo está organizado na primeira e segunda classe. $O$ trabalho docente no início da carreira constitui o segundo eixo discursivo e está sumarizado nas classes 3, 4 e 5. Na Figura 1, a seguir, apresentamos as cinco classes, que estão articuladas e sintetizam os conteúdos que demarcam as representações sociais do ser professor.

Figura 1: Dendrograma referente à Classificação Hierárquica Descendente (CHD) do corpus ${ }^{5}$

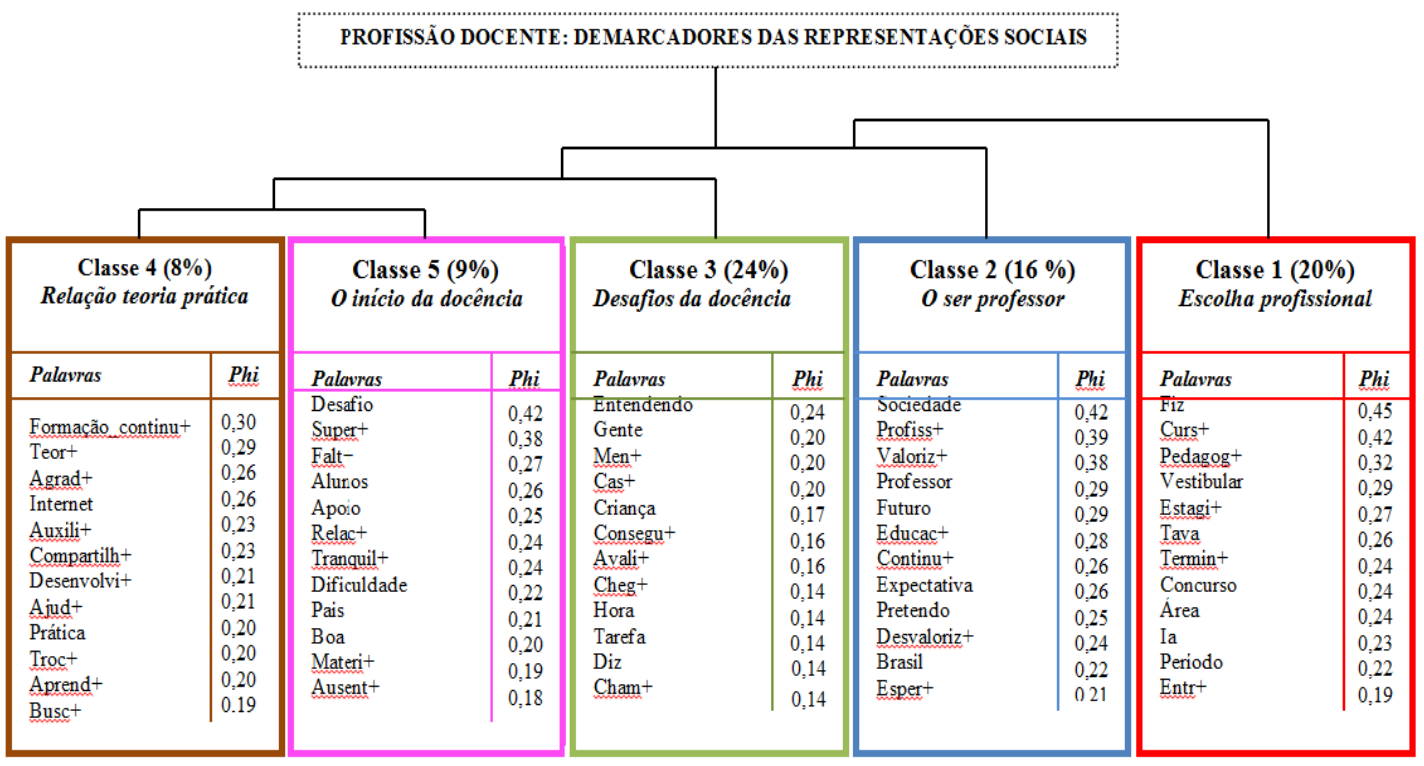

Fonte: Elaborado pela autora

\section{Classe 1: Escolha profissional}

A Classe 1, denominada "Escolha profissional", organiza 20\% das UCEs e representa o segundo contexto temático mais significativo dos dados apurados pelo programa. Esta classe agrega os depoimentos relacionados à escolha e ingresso em curso de formação de professores. Em primeiro lugar, os sujeitos fazem menção à influência de familiares para a escolha profissional; destacam ainda o gosto por

${ }^{5}$ dados da própria pesquisa. 
trabalhar com crianças e pelo conteúdo específico que lecionam. Além disso, destacam a importância desempenhada por professores que os acompanharam durante a trajetória escolar. Alguns relembram a tentativa de ingresso em outros cursos, mas que não obtiveram sucesso ou que atuavam em outros campos afins e sentiram a necessidade de um suporte para assumir a função de professor. Comentam:

Minha razão foi totalmente familiar, pois minha mãe é educadora e sempre nos incentivou a seguir a profissão [...]. Sou de uma família de quatro irmãos e três deles possuem um curso de licenciatura de áreas diferentes. (PEF-15)

Tenho tias que são professoras, e lembro que sempre admirei a profissão [...]. Quando criança sempre brincava de escolinha (PEF-12)

Eu sempre gostei muito de crianças, eu ia fazer pediatria, só que eu tinha uma deficiência na questão de Química, Física, então [...] eu pensei em outra profissão que poderia atuar com crianças. Então eu escolhi Pedagogia (PEI-2)

[...] Minhas irmãs são professoras e eu vivenciava muito o trabalho delas [...] Então resolvi ser professora. (PEF-14)

Fiz História porque gostava da matéria, mas sem pensar muito no trabalho de professora. Aos poucos fui gostando e me interessando. $\mathrm{O}$ ambiente escolar é algo que me atrai bastante, me sinto bem. (PEF-13)

[...] antigamente eu detestava geografia, mas no ensino médio eu tive um professor de geografia que era muito bom, então foi a partir dele que eu me interessei pela profissão. (PEF-18)

Assim como pontuaram os docentes, Valle (2006), ao estudar a procura pelos cursos de formação de professores, indica que a escolha profissional pode estar relacionada à subjetividade dos sujeitos, valores altruísticos e de realização pessoal, a imagem que os mesmos têm de si, bem como às experiências vividas no cotidiano.

As referências à influência das famílias, comuns a grande parte dos entrevistados, vem corroborar o que Passeggi (2006, p. 04) caracteriza como transmissão intergeracional, ou seja, a influência de familiares, pais, irmãos e primos, na escolha pela profissão. Segundo ela, a instituição familiar geraria "[...] senão um ambiente de reprodução profissional, mas, pelo menos, um clima de sensibilização vocacional, levando a uma apropriação do desejo do outro, seja por dependência, seja por respeito, e não a uma resistência no processo de decisão".

6 Codificamos os participantes utilizando a letra P (abreviatura de professor) seguida EF ou EI (abreviaturas de Ensino Fundamental ou Educação Infantil) e o ${ }^{\circ}$ do protocolo de entrevista. 
Do conteúdo organizado na Classe 1 podemos depreender que os motivos para a escolha profissional dos docentes em início de carreira envolvem uma rede complexa de diferentes fatores de ordem cultural que concorrem para formulação de uma representação social da docência.

\section{Classe 2: O ser professor}

A segunda classe, intitulada "O ser professor", corresponde a $16 \%$ do corpus analisado pelo programa e organiza os depoimentos relacionados ao simbólico sobre a profissão, associando-o às múltiplas funções assumidas pelo docente junto aos alunos, às dificuldades, desafios e perspectivas profissionais. De modo geral simbolizam a profissão como importante e ao mesmo tempo desvalorizada. Eis o que dizem:

Ser professor significa transmitir conhecimento, incentivar o aluno a ser alguém com uma profissão que garanta um futuro bom. Ser professor hoje em dia também e ser um pouco mãe, amiga e às vezes psicóloga porque os alunos são carentes de atenção. (PEF-30)

É uma profissão em que se tem uma responsabilidade muito grande e, assim, você acaba também assumindo responsabilidades que não são suas [...]. Nós somos responsáveis pelas duas educações, porque além da nossa responsabilidade em sala, temos de formar cidadão críticos, pensantes sobre o meio, a gente também tem que dar educação doméstica, ensinando posturas, comportamentos, enfim assumimos muitas responsabilidades (PEF-18)

Professor pra mim é poder participar ativamente da construção do cidadão, da formação do cidadão. (PEI-8)

Ser professor na atualidade é ser corajoso, porque há uma a grande falta de valorização da educação, falta de estrutura na escola, o acesso à educação também está difícil. (P-EF21)

São fartos os depoimentos, porém o que foi possível detectar em relação ao ser professor é uma representação centrada em múltiplos elementos, prevalecendo a transmissão e mediação de conhecimentos, possibilidade de formar e educar sujeitos em diferentes dimensões, o compromisso e responsabilidade envolvidos na tarefa de educar e, principalmente, a precarização e desvalorização do professor na sociedade. Mesmo que atrelado ao gosto e amor pelo trabalho, esses elementos foram consensuais nos diferentes grupos de professores de educação infantil e nos anos iniciais e finais do ensino fundamental.

Ainda nessa classe foram localizadas referências às perspectivas profissionais dos entrevistados. Como atestam os seus depoimentos, há um misto de desencanto e interesse de permanência na profissão. Especialmente os professores que atuam no 
ensino fundamental foram os mais indecisos ou indispostos a persistirem no exercício profissional. Eles comentaram:

[...] eu penso que será muito difícil eu continuar sendo professor, porque não há reconhecimento [...] realmente é muito difícil porque assim quando um professor tem que ficar trabalhando em três escolas para que o salário dele seja um pouco melhor. É muito complicado, acho que ninguém mais vai querer ser, estamos em uma berlinda, acho que quem está quer sair e quem pensa em entrar desiste logo da carreira. (PEF-21)

Não sei se continuo na docência. Eu espero que a situação educacional melhore, pois do jeito que está não teremos mais professores no futuro. (PEF-26)

[...] pretendo continuar na docência sim! Mas eu quero um lugar que me dê melhores condições de trabalho [...] pretendo atuar na docência e pretendo fazer isso em outros níveis, eu não sei assim a nível superior em uma instituição pública, mas pretendo buscar outras oportunidades também... (PEI-9)

Sim! Vou ser professora pelo resto da vida, mas mais na frente eu vou fazer mestrado, doutorado... Mas sair da educação eu não quero. Até algumas pessoas falam: Ah! por que tu não ensina no nível superior? Mas, não é o que eu quero, eu me realizo na educação infantil e mesmo que paguem mal, que não seja reconhecido, que tenha os problemas que tem, mas eu pretendo continuar na educação infantil. (PEI-1)

Os resultados apresentados na classe 2 são indicativos de uma representação social do ser professor pautada numa relação de ambiguidade. Por um lado, trata-se de uma profissão importante capaz de construir e favorecer todas as outras e, por outro, é simbolicamente vista como uma profissão precarizada, com múltiplas exigências, mal remunerada e sem o devido reconhecimento social. Como as representações são orientadoras das práticas há uma tendência da maior parte do grupo pesquisado resistir frente à possibilidade de permanecer na carreira que estão iniciando.

\section{Classe 3: Desafios da docência}

A Classe 3, os desafios da docência, congrega 24\% das UCEs, ou seja, é a classe com maior produção discursiva dos sujeitos entrevistados, dela depreendemos o cenário no qual estão sendo construídas as representações sociais do ser docente pelos profissionais em início de carreira. Diz respeito às múltiplas atividades, dificuldades e limitações que assumem no interior da escola. Pelos depoimentos, a tarefa principal é mediar o processo ensino aprendizagem, contudo ela acaba comprometida em função da 
falta de infraestrutura das escolas, ausência de material didático e recursos tecnológicos, além do não estabelecimento de parceria com as famílias dos alunos. Eis algumas declarações nesse sentido:

\begin{abstract}
Alguns pais são presentes e outros só deixam as crianças e vão embora, outros são usuários de drogas. [...] Só tem dois pais mesmo que frequentam e são assíduos e se preocupam em saber quais atividades fizeram (PEI-1).

As dificuldades e os desafios são muitos... Passaria a tarde falando... Mas, vamos lá $[. .$.$] "criaram" um conceito de que escola é lugar pra$ educar, ensinar, alimentar e tomar conta de seus filhos... Além do que tem aqueles que só colocam o filho na escola pra receber bolsa do governo... Às vezes temos que ser psicóloga, mãe e delegada em sala de aula (PEF-15)

O desafio principal são as condições de trabalho. São muitas aulas, salas superlotadas, muitas cadernetas para dar conta, então tenho muitas turmas, acho que o currículo atual também não é muito adequado para os estudantes, para as demandas, a escola tem pouca estrutura para tecnologias (PEF-20).
\end{abstract}

Nesta classe 3 localizamos os depoimentos mais relacionados à precarização do trabalho docente e suas implicações para imposição dos desafios à prática pedagógica. Sabemos que é no universo sociocultural que estão e são continuamente produzidas representações sociais. Como diz Moscovici (1978), se quisermos saber por que uma pessoa se comporta de um jeito e não de outro devemos primeiramente compreender o seu cotidiano e as relações que nele se estabelecem. Nossas reações frente às pessoas e os objetos sociais são mediadas pelas representações sociais que delas fazemos. As dificuldades vivenciadas pelos professores afetam negativamente sua prática pedagógica e fazem com que eles estejam, já no início da carreira, construindo representações pouco promissoras do ser professor. Eles concretizam ou objetivam a profissão docente na precarização.

\title{
Classe 4: Relação teoria prática
}

A quarta classe, Relação teoria prática, corresponde a $8 \%$ do corpus e organiza os depoimentos relacionados à formação (inicial e continuada) e sua contribuição para o trabalho docente. Como pontua Roldão (2007), dois processos concorrem para a profissionalização do professorado, quais sejam, a institucionalização da escola e do currículo e a afirmação de um conhecimento profissional específico corporizado. Considerando o papel distintivo do saber específico no desenvolvimento profissional 
docente, procuramos identificar como esse saber tem se articulado ou contribuído para a prática docente dos professores em início de carreira. Sobre esse aspecto comentaram:

Eu sinceramente... Assim... Geografia mesmo você só aprende na sala de aula, infelizmente assim a faculdade deixa a desejar... Em relação à formação continuada, essa tem me ajudado bastante porque lá tem experiências de outros professores, mostram os conteúdos que são mais atuais então tem sido importante. Apoio para as práticas... Eu procuro em internet nesses grupos mesmo de whatsapp, no nodo grupo de formação continuada nós temos espaço para mandar artigos um para o outro, compartilhamos artigos, vídeos (PEF-19)

Na minha experiência, tanto a formação inicial da graduação quanto à formação continuada, seja na especialização ou no mestrado, elas contribuem positivamente [...] justamente porque tendo um processo de reflexão entre a teoria e a prática. Para mim, essa questão é constantemente ressignificada (PEI-05)

Tenho muitas experiências. [...] Sempre levo as mesmas pra sala de aula, pois essas formações são ricas em metodologias e didáticas tanto práticas quanto pedagógicas que nos auxiliam e nos ajudam bastante na docência. (PEF-14)

Vou lhe ser sincero, o que aprendemos na faculdade não condiz com a realidade das condições de ensino da rede pública, é como começar do zero. A experiência vai ser realmente com a licenciatura prática na escola... (PEF-17)

O que vemos na faculdade é totalmente diferente da realidade da sala de aula. Sobre a formação continuada [...] ajuda um pouco... (PEF-31)

Constatamos pelas falas que foi mais enfatizada pelos professores a desarticulação entre formação e práticas. Poucos foram os que destacaram o valor e importância do saber sistemático adquirido para a prática pedagógica. Os professores que atuam no ensino fundamental, aqueles com formação em licenciaturas diversas, foram os mais críticos para com a formação inicial e continuada. Os docentes que atuam na educação infantil fizeram referências mais positivas à possibilidade de vincular teoria e prática.

Como demonstra a produção discursiva da Classe 4, a maioria dos professores iniciantes reconhece a formação inicial com forte carga teórica; isto vai corroborar o que colocam Giovanni e Marin (2014): segundo esses autores os docentes tem muito a aprender sobre o entorno, as regras e normas da escola, alunos e suas diferenças, além de quais condutas adotar nas situações de indisciplina, conflito e violência escolar, tão comuns no dia a dia da educação pública. Apesar de relevantes para o exercício da profissão, vários desses aspectos são pouco abordados na formação inicial e continuada. 
Essas formações não têm conseguido articular de modo suficiente o conteúdo formativo aos elementos da cultura escolar.

\section{Classe 5: O início da docência}

A classe 5, o Início da Docência, corresponde a 9\% do corpus analisado e organiza os sentimentos e pontos marcantes da fase inicial da profissão. Os docentes falam:

[...] o mais marcante foi me deparar com situações que eu não sabia como agir na hora. Superei esses obstáculos com a ajuda dos professores. (PEI-1)

[...] a compreensão que o pais não tem do nosso trabalho, tem certos pais, a grande maioria não compreende o que a gente faz aqui. Eles acham que o menino vem pra cá pra brincar, que a gente não faz nada. (PEF-4)

[...] a falta de educação doméstica dos alunos, muitos fazem barulho no momento da explicação, falam palavrão, desrespeitam professores e colegas. Eu tento mostrar para eles que a conduta está errada [...] Mas, tudo é desfeito porque passam menos tempo na escola [...] Salas muito lotadas é difícil dá atenção a todos. (PEF-30)

O mau comportamento, a má postura dos meninos em sala de aula, o linguajar, os palavrões. (PEF-28)

[...] o mais marcante e que me incomoda é o desinteresse e indisciplina de alguns alunos. Eles geralmente têm um vocabulário bem agressivo, às vezes soltam palavrões... (PEF-27)

Como se pode detectar nos depoimentos acima, são as dificuldades relacionadas ao trabalho do docente no cotidiano, e obstáculos relacionados às relações interpessoais, os pontos mais marcantes do início da carreira dos docentes. Os docentes de educação infantil enfatizaram a relação com as famílias das crianças e aqueles que atuam no ensino fundamental expuseram mais questões referentes aos alunos, especialmente indisciplina e falta de interesse pelos estudos.

O conteúdo da classe 5 confirma o que já foi constatado por outros autores sobre a inserção profissional docente (Conti, 2003; Donato e Ens, 2009 e Nono, 2011). Essa literatura indica situações de sofrimento e mal-estar, vivenciadas pelos docentes no processo de adaptação ao trabalho docente. O esforço emocional e cognitivo que despendem não se reverte de maneira positiva, de modo a continuarem com o entusiasmo inicial. 


\section{Considerações finais}

Entendemos que as representações sociais constituem um conjunto organizado e estruturado de informações, crenças, opiniões e atitudes que orientam as práticas e condutas dos sujeitos. Esse material simbólico sobre o ser professor revela um amálgama que envolve a escolha profissional, o trabalho docente, a relação teoria e prática, os desafios e perspectivas para a docência.

A partir dos resultados obtidos podemos afirmar que os docentes apresentam como maior justificativa para a escolha a influência familiar. Conforme demonstrado, a convivência com profissionais no grupo de socialização primária tem sido decisiva para se chegar a ser professor. Esse contexto inicial vai construindo e sedimentando as representações da profissão.

O trabalho docente é de modo quase consensual associado à precarização da docência. Essa precarização foi concretizada em dificuldades de toda ordem, sendo mais enfatizadas as de infraestrutura das escolas, falta de material didático, relações interpessoais complicadas entre famílias e os próprios alunos. Diferentemente do que tem sido comum na literatura (LIMA et al 2006; CONTI, 2003; DONATO; ENS, 2009; NONO, 2011), não detectamos grandes problemas de acolhimento dos iniciantes nas escolas, tampouco obstáculos na sua interação com os pares. O choque de realidade ficou mais explicito entre os professores iniciantes que atuam nos anos finais do ensino fundamental. O referido impacto foi associado diretamente à indisciplina e desinteresse dos adolescentes.

No que tange às perspectivas profissionais do grupo percebemos um certo desânimo para com a possibilidade de permanecerem na profissão. Contudo, há aqueles que desejam prosseguir mesmo que seja em outros níveis ou modalidades de ensino. Essa possibilidade foi muito mais apontada por professores de educação infantil.

Em suma, detectamos como elementos demarcadores das representações sociais da profissão docente por professores em início de carreira: a transmissão e mediação de conhecimentos, a possibilidade de formar e educar sujeitos em diferentes dimensões, o compromisso e a responsabilidade envolvidos na tarefa de educar e, principalmente, a precarização e desvalorização do professor na sociedade.

Os resultados sinalizam e reforçam a necessidade de elaboração de programas vinculados às políticas públicas - que ofereçam maior suporte ao trabalho do professor 
em início de carreira, estimulando-o a permanecer na docência de modo a melhor qualificar a educação.

\section{REFERÊNCIAS}

CAMARGO, B. V. ALCESTE: um programa informático de análise quantitativa de dados textuais. In: MOREIRA A. S. P. (Org). Perspectivas teórico-metodológicas em representações sociais. João Pessoa: UFPB/Ed Universitária. 2005. p. 511-539

CONTI, C. L. A. Imagens da profissão docente: um estudo sobre professoras primárias em início de carreira. 2003. 177 f. Tese (Doutorado em Educação) Faculdade de Educação, UNICAMP, Campinas-SP, 2003.

CORREAA, P. M; PORTELLA, V. C. M. As pesquisas sobre professores iniciantes no Brasil: uma revisão. Olhar de professor, Ponta Grossa, v. 15n. 2, p. 223-236, 2012.

DOISE, W. Atitudes e representações sociais. In: JODELET, Denise. (Org) As representações sociais. Rio de Janeiro: EdUERJ, 2001. p. 187-204.

DONATO, S. P.; ENS, R. T. Representações sociais do ser professor no contexto atual - Desafios, incertezas e possibilidades. IX CONGRESSO NACIONAL DE

EDUCAÇÃO - EDUCERE. Formação de professores. 26 a 29 de outubro, PUCPR, Paraná. p. 6863 -6876. 2009.

GARCÍA, M. C. Formação de professores para uma mudança educativa. Porto: Porto, 1999.

GIOVANNI, L. M.; MARIN, A. J. Professores iniciantes diferentes necessidades e diferentes contextos. Junqueira e Marin editores. Araraquara, SP, 2014.

HUBERMAN, M. O ciclo de vida profissional dos professores. In: NÓVOA, A António (Org.). Vidas de professores. 2. ed. Porto: Porto Ed. 1995. p. 31-61.

JODELET, D. Representações Sociais: um domínio em expansão. In: JODELET, D. As representações sociais. Rio de Janeiro: EdUERJ, 2001, p. 17-44.

LIMA, E. F. (Org.) Sobrevivências no início de carreira. Brasília: Líber Livro Editora, 2006.

MACHADO, L. B.; ANICETO, R. de A. Núcleo central e periferia das representações sociais de ciclos de aprendizagem entre professores. Ensaio de Aval. e Pol. Pub. em educação. RJ, v.18, n.67, 2010. p. 345-363.

MACHADO, L. B. Aproximações em torno da zona muda das representações sociais de ciclos aprendizagem entre professores. ETD - Educação temática digital. Campinas, SP v.14 n.2 p.186-201. jul./dez. 2012

MINAYO, M. C. de S. O desafio do conhecimento: pesquisa qualitativa em saúde. 11 ed. São Paulo: Editora Hucitec, 2008. 
MOSCOVICI, S. A Representação Social da Psicanálise. Zahar Editores: Rio de Janeiro, 1978.

MOSCOVICI, S. A psicanálise, sua imagem e seu público. Petrópolis, RJ: Vozes, 2012.

NONO, M. A. Professores Iniciantes: O papel da escola em sua formação. Porto Alegre: Ed. Mediação. 2011.

PAPI, S.; MARTINS, P. Professores iniciantes: as pesquisas e suas bases teóricometodológicas. Linhas Críticas, Brasília, v. 14, n. 27, p.251-269, jul./dez. 2009.

PAPI. S. O. G.; CARVALHO, C. B. Professores iniciantes: um panorama das investigações brasileiras. Olhar de professor, Ponta Grossa, 16(1): 185-202, 2013.

PASSEGGI, M. da C. Formação e pesquisa autobiográfica. In: CONGRESSO INTERNACIONAL SOBRE PESQUISA (AUTO)BIOGRÁFICA, 2006, Salvador. Anais/Resumos... Salvador: UNEB, 2006. CD-ROM.

ROLDÃO, M. do C. Função docente: natureza e construção do conhecimento profissional. Revista Brasileira de Estudos Pedagógicos. Abr., v.12, n. 34, p. 94-103. 2007.

VALLE, I. R. Carreira do magistério: uma escolha profissional deliberada? Revista Brasileira de Estudos Pedagógicos. v. 87, p. 178-187. Brasília, 2006.

\section{Como referenciar este artigo}

MACHADO, Laeda Bezerra. Profissão docente: elementos demarcadores das representações sociais de professores em início de carreira. Revista Ibero Americana de Estudos em Educação, Araraquara, v. 13, n. 03, p. 1132-1148, jul./set., 2018. EISSN:1982-5587. DOI: 10.21723/riaee.v13.n3.2018.9094

Submetido em: 23/11/2016

Aprovado em: 05/06/2017 